\title{
Characteristics of oven-dried Jerusalem artichoke powder and its applications in phosphate-free emulsified chicken meatballs
}

\section{Öztürk, B. ${ }^{*}$; Serdaroğlu, M.}

Food Engineering Department, Engineering Faculty, Ege University, Bornova, Izmir, Turkey.

*E-mail of the corresponding author: burcu.ozturk@ege.edu.tr

\begin{abstract}
In this study, we aimed to investigate chemical and technological characteristics of oven-dried Jerusalem artichoke powder (JAP) to be further incorporated into emulsified chicken meatballs (with/without sodium carbonate) as sodium tripolyphosphate (STPP) replacers. The dietary fiber content of JAP was quite high to improve the health profile of the meat system. JAP samples showed equivalent technological quality to industrial inulin in terms of water-holding, oil-binding, emulsification and gelling abilities. Phosphate-free meatballs formulated with JAP and sodium carbonate had better health impacts compared with phosphate containing meatballs while cooking characteristics were similar. The results showed that oven-dried JAP presented a good health profile and high technological quality to be evaluated as inorganic phosphate replacers in formulation of emulsified poultry products.
\end{abstract}

Keywords: Jerusalem artichoke, oven-drying, emulsified chicken meatball, sodium tripolyphosphate, phosphate-free 


\section{Introduction}

Jerusalem artichoke (Helianthus tuberosus L.) is a natural raw material which highly contains fiber, minerals and vitamins. The tubers are known to be a health-promoting food source that contains inulin, a soluble dietary fiber, instead of starch as a carbohydrate reserve [1, 2]. Today utilization of natural ingredients in the formulation of meat products as phosphate replacers has come into prominence as a novel topic due to health concerns about chemical additives. Phosphates have a common use to improve quality of various meat products by shifting the $\mathrm{pH}$ away from isoelectric point, thereby increasing protein functionality and water-holding capacity and enhancing overall quality attributes, however, due to the emerging and newly identified health risks associated with phosphates, there has been a tendency to decrease the amount of their levels in meat product formulations [3-5]. Therefore, Jerusalem artichoke is a promising ingredient that could be used as an economic source of functional components in phosphate-free meat product formulations. In this study, we aimed to investigate chemical and technological characteristics of oven-dried Jerusalem artichoke powder (JAP) to be further incorporated into emulsified chicken meatballs (with/without sodium carbonate) as a clean-label sodium tripolyphosphate (STPP) replacer.

\section{Materials and Methods}

\subsection{Production of Jerusalem artichoke powder (JAP) and emulsified chicken meatballs}

Jerusalem artichoke powder (JAP) was produced from fresh and non-damaged tubers. The tubers were obtained from a local producer in Izmir region, washed with tap water, peeled and immediately immersed in citric acid (\%1) solution to avoid enzymatic color changes. The tubers were then sliced into $0.2 \mathrm{~mm}$ thickness (Berkel Slicers, Italy). Slices were then air-dried in an industrial drying oven (Defne Spices Co., Izmir) at $60 \pm 5^{\circ} \mathrm{C}$ for $8 \mathrm{~h}$. The dried slices were finally ground through a hammer mill (Brook Crompton, UK) and sieved through $0.5 \mathrm{~mm}$. JAP was stored in glass jars prior to meatball production.

Chicken meatballs were formulated either with STPP (control) or JAP and/or sodium carbonate (SC) as STPP replacers. 70\% of the chicken breast muscle was minced through 8 mm plate. The rest of the breast muscles (30\%) and chicken skin were minced through 3 $\mathrm{mm}$ plate and then emulsified with $\mathrm{NaCl}$, STPP, rosemary extract and ice at $4400 \mathrm{rpm}$ for 5 min (control) in a bowl cutter ( $\mathrm{K}+\mathrm{G}$ Wetter, Germany). Other treatments were prepared using $3.8 \%, 5.7 \%$ or $7.6 \%$ JAP, with or without $0.2 \%$ SC as STPP replacers. After the emulsification procedure, the emulsions were mixed with $8 \mathrm{~mm}$ minced breast muscle and the doughs were cold-set at $0^{\circ} \mathrm{C}$ for $1 \mathrm{~h}$. After that, the doughs were portioned with molds 
and cold-set again at $-18^{\circ} \mathrm{C}$ for $20 \mathrm{~min}$. Meatballs were then deep-fat fried with canola oil in an electric fryer (Inoksan, Turkey) at $180 \pm 2^{\circ} \mathrm{C}$ for $3 \mathrm{~min}$. The samples were cooled at $4^{\circ} \mathrm{C}$ prior to analysis.

\subsection{Methods}

\subsubsection{Characteristics of JAP}

Proximate analysis was performed in order to determine total moisture [6], lipid [6], ash [6] and protein [7] content. The water-soluble dietary fiber content of JAP samples was analyzed by Megazyme dietary fiber assay kit (Megazyme International Ireland Ltd., Wicklow, Ireland) according to AOAC [8]. Sucrose, D-glucose and D-fructose concentrations in JAP samples were determined by enzymatic assay (Boehringer Mannheim, R-Biopharm, Germany). In order to evaluate technological quality of JAP samples; water-holding capacity (WHC) [9], oil-binding capacity (OBC) [10], emulsifying capacity (EC) [11] and volumetric gel index (VGI) [12] were analyzed.

\subsubsection{Characteristics of emulsified chicken meatballs}

The dietary fiber content of meatball samples was calculated from the dietary fiber content and incorporation amount of JAP in meatball formulations. The salt content of the samples was determined according to Mohr method [6]. Cook yield (CY) of the samples were calculated from the weight of pre-cooked and cooked samples according to Murphy et al. [13]. Data was statistically analysed by SPSS software with one-way ANOVA and Duncan Post-hoc tests.

\section{Results and Discussions}

\subsection{Characteristics of JAP}

The initial moisture content of fresh Jerusalem artichoke tubers was $82.9 \%$, while the final moisture content of JAP was 5.31\%, which indicated that approximately $93 \%$ of the water in the raw material could be removed by drying operation. Some images from dried samples could be seen in Fig. 1. Sucrose, D-glucose and D-fructose content of JAP samples were $18.11 \mathrm{~g} / 100 \mathrm{~g}, 2.6 \mathrm{~g} / 100 \mathrm{~g}$, and $5.8 \mathrm{~g} / 100 \mathrm{~g}$, respectively. Other than that, JAP samples had $11.96 \%$ protein, $5.81 \%$ ash, and $2.09 \%$ lipid. Similar results were previously reported by Praznik et al. [14]. The dietary fiber content of JAP samples was recorded as $58.76 \%$, which is more than half of the chemical composition. This result indicated that dried Jerusalem artichoke tubers represent considerable potential for increasing dietary fiber content and so improving health-promoting effects of meat products as a natural and nutritious ingredient. Our findings were in accordance with Khuenpet et al. [15], who found that inulin content of JAP was 54.86/100 g. The composition of the tubers could differ 
depending on varieties, harvesting maturity, storage time, growing conditions and processing technique $[14,15]$.
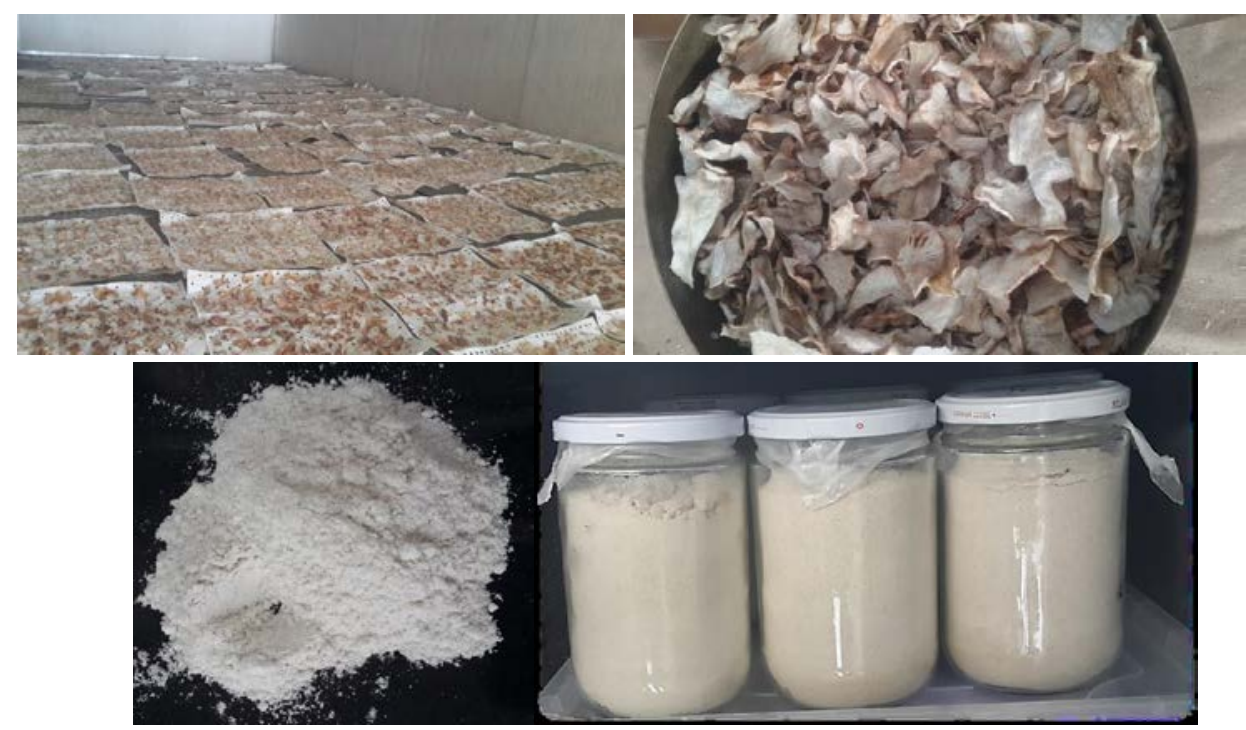

Fig. 1 Some images of dried Jerusalem artichoke tubers and the final product

Technological characteristics of JAP samples were as follows: WHC, OBC, and EC of the samples were $3.03 \pm 0.60 \mathrm{ml}$ water $/ \mathrm{g}, 3.63 \pm 0.45 \mathrm{ml}$ oil $/ \mathrm{g}$ and $150.0 \pm 7.0 \mathrm{ml} \mathrm{oil} / \mathrm{g}$, respectively. Afoakwah et al. [16] reported that oven-dried JAP had $4.30 \pm 0.10 \mathrm{~g}$ water/g WHC and $2.06 \pm 0.03 \mathrm{~g}$ oil/g OBC, and they stated that OBC of JAP are higher than many other fibers. In their study, freeze-dried JAP samples had higher OBC $(3.02 \pm 0.14 \mathrm{~g}$ oil/g) compared to oven-dried samples, but the values were not as high as our results, probably due to the different origin of the raw materials. Rodríguez-Furlán et al. [9] reported that chicory inulin had $100 \pm 5 \mathrm{~mL}$ oil/g product EC. This result showed that JAP had a better emulsification ability compared to industrial inulin.

VGI values of JAP samples were recorded as $10.1 \pm 1.2 \%, 53.3 \pm 4.8 \%$ and $100.0 \pm 0.0 \%$ in $5 \%, 10 \%$ and $25 \%(\mathrm{w} / \mathrm{v})$ water solutions, respectively. This result showed that an initial partial gel formation was observed in $5 \%$ water solution, whilst JAP samples were able to form a total gel structure in $25 \%$ water solution. Gel formation ability of JAP is a considerable quality attribute since the composite gel structure formed after hydrating and swelling of the samples could easily be distributed when used in the meat matrix. Kim et al. [12] reported that 30 and 35\% inulin suspensions made $100 \%$ gel structure. Thus, JAP 
samples could form a gel structure in lower concentrations compared to inulin, in other words gel formation ability was higher in JAP samples than in inulin samples.

\subsection{Characteristics of emulsified chicken meatballs}

The dietary fiber and salt content of emulsified chicken meatballs are presented in Table 1 . Since the dietary fiber content of the meatballs was calculated based on the dietary fiber content of JAP samples, expectedly the values were increased with added JAP. According to this, the samples formulated with $3.8 \%$ JAP had $2.23 \%$ dietary fiber, while the samples formulated with $7.6 \%$ JAP had $4.46 \%$ dietary fiber. This result showed that in phosphatefree meat product formulations, utilization of JAP would lead to increase dietary fiber content and thus improve the health profile of the product, besides to provide technological advantages. The salt content of the samples was between $0.77-0.97 \%$, which was significantly affected by formulation $(P<0.05)$. The highest salt content was recorded in samples containing STPP (P group), while the lowest salt content was recorded in samples containing 7.6\% JAP (J3 and JC3 groups) $(P<0.05)$. The relatively higher salt contents of $P$ and $\mathrm{C}$ samples among treatments could be arised from the sodium content of these samples. It was noted that increased concentrations of JAP were effective to reduce salt content regardless of sodium carbonate incorporation. This result could be due to the increase in the dietary fiber content with added JAP, which might dilute the sodium chloride used in the formulation.

Table 1. The dietary fiber and salt content of emulsified chicken meatballs

\begin{tabular}{ccc}
\hline Treatments* & Dietary fiber content (\%) & Salt content (\%)** \\
\hline P & 0.00 & $0.97^{\mathrm{a}} \pm 0.01$ \\
C & 0.00 & $0.95^{\mathrm{b}} \pm 0.02$ \\
J1 & 2.23 & $0.88^{\mathrm{c}} \pm 0.01$ \\
JC1 & 2.23 & $0.87^{\mathrm{c}} \pm 0.03$ \\
J2 & 3.35 & $0.82^{\mathrm{d}} \pm 0.01$ \\
JC2 & 3.35 & $0.82^{\mathrm{d}} \pm 0.01$ \\
J3 & 4.46 & $0.78^{\mathrm{e}} \pm 0.01$ \\
JC3 & 4.46 & $0.77^{\mathrm{e}} \pm 0.01$
\end{tabular}

\footnotetext{
* The meatballs were formulated with P: $0.5 \%$ STPP, C: $0.2 \% \mathrm{Na}_{2} \mathrm{CO}_{3}, \mathbf{J 1}: 3.8 \%$ JAP, JC1: $3.8 \% \mathrm{JAP}+0.2 \%$ $\mathrm{Na}_{2} \mathrm{CO}_{3}$, J2: 5.7\% JAP, JC2: 5.7\% JAP+0.2\% $\mathrm{Na}_{2} \mathrm{CO}_{3}$, J3: 7.6\% JAP, JC3: 7.6\% JAP+0.2\% $\mathrm{Na}_{2} \mathrm{CO}_{3}$.

** Data are presented as the mean values of replications \pm standard deviation of the mean. abcd: Means with the different letter in the same column are significantly different $(P<0.05)$.
}

Cook yield (CY) of the treatments are shown in Fig. 2. The values were between 77.1990.96\% and significant changes among treatments were recorded $(P<0.05)$. Samples with JAP and sodium carbonate (JC1, JC2, and JC3) showed similar CY to each other, but JC2 samples had higher CY than samples with STPP (P). This data indicated that JC2 samples 
showed a better performance than P samples to reduce fluid losses upon cooking. It was concluded that fiber-sourced ingredients have an important effect to meet the behaviors of phosphates by their water-holding ability in case of appropriate $\mathrm{pH}$ values. Our results were in agreement with Prabhu and Husak [17], who reported that utilization of native potato starch and sodium carbonate was effective to increase CY of phosphate-free pork loins.

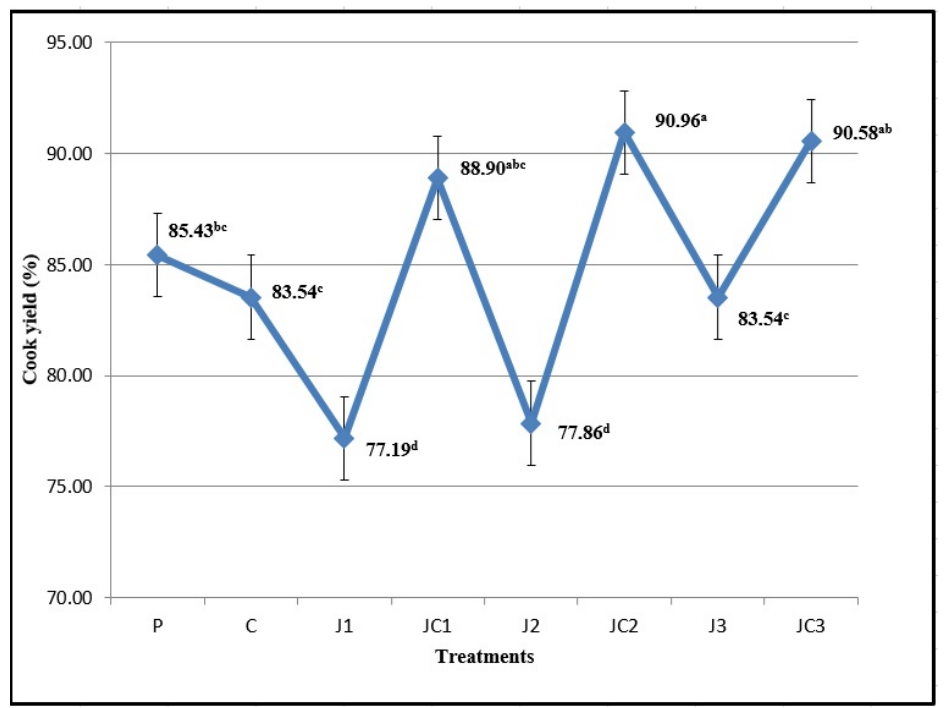

Fig. 2 Cook yield of emulsified chicken meatballs. The meatballs were formulated with $P: 0.5 \%$ STPP, C: 0.2\% $\mathrm{Na}_{2} \mathrm{CO}_{3}, \mathrm{J1}: 3.8 \% \mathrm{JAP}, \mathrm{JC1}: 3.8 \% \mathrm{JAP}+0.2 \% \mathrm{Na}_{2} \mathrm{CO}_{3}, \mathrm{~J} 2: 5.7 \% \mathrm{JAP}, \mathrm{JC2}: 5.7 \%$ $\mathrm{JAP}+0.2 \% \mathrm{Na}_{2} \mathrm{CO}_{3}, \mathrm{~J} 3: 7.6 \% \mathrm{JAP}, \mathrm{JC} 3: 7.6 \% \mathrm{JAP}+0.2 \% \mathrm{Na}_{2} \mathrm{CO}_{3}$. The standard deviation of the means ranged between 1.93-4.49. $a, b$, $c$ : different letters indicate significant difference among means $(P<0.05)$.

\section{Conclusions}

The results of the present research showed that oven-dried JAP is a health-promoting ingredient in terms of high dietary fiber content and also it has technological advantages over industrial inulin. Utilization of JAP in combination with sodium carbonate in emulsified chicken meatballs have a good potential to enhance the dietary fiber content and reduce the salt content of the product, simultaneously to increase cook yield. Overall, it was concluded that oven-dried JAP presented a good health profile and high technological quality with the aid of SC to be evaluated as inorganic phosphate replacers in formulation of emulsified poultry products. 


\section{Acknowledgement}

The authors would like to extend special thanks to the Republic of Turkey, Ministry of Science, Industry, and Technology for financial support to this study with Project No: 0764.STZ.2014 (SAN-TEZ Program), and many thanks to the co-partner company (Abalıŏlu Co., Izmir).

\section{References}

[1] Yang, L.; He, Q.S.; Corscadden, K.; Udenigwe, C.C. The prospects of Jerusalem artichoke in functional food ingredients and bioenergy production. Biotechnology Reports 2015, 5, 77-88.

[2] Kays, S.J.; Nottingham, S.F. Biology and Chemistry of Jerusalem Artichoke: Helianthus tuberosus L.; Taylor \& Francis Group, New York, 2007.

[3] Sebranek, J. Basic curing ingredients. In Ingredients in meat products: properties, functionality and applications; Tarté, R., Ed.; Springer Publishing: USA, 2008; 1-23.

[4] Petracci, M.; Bianchi, M.; Mudalal, S; Cavani, C. Functional ingredients for poultry meat products. Trends in Food Science and Technology 2013, 33 (1), 27-39.

[5] Lampila, L.E. Applications and functions of food-grade phosphates. Annals of New York Academy of Sciences 2013, 1301, 37-44.

[6] AOAC. Offical Methods of Analysis; 19th Ed.; Association of Offical Analytical Chemists; Gaithersburg, MD, USA, 2012.

[7] AOCS. American Oil Chemists' Society Official Methods and Recommended Practices of the AOCS; 5th Ed.; American Oil Chemists' Society, Champaign, USA, 2004.

[8] AOAC. Offical Methods of Analysis; 16th Ed.; Association of Offical Analytical Chemists; Gaithersburg, MD, USA, 1995.

[9] Rodríguez-Furlán, L.T; Padilla, A.P.; Campderrós, M.E. Development of reduced fat minced meats using inulin and bovine plasma proteins as fat replacers. Meat Science 2014, 96 (2A), 762-768.

[10] Chakraborty, P. Coconut protein isolate by ultrafiltration. In Food engineering and process applications; Meguer, M.L.; Jelen, P., Eds.; Elsevier Applied Science Publishers, New York, USA, 1986; 308-315. 
[11] Rodríguez-Furlán, L.T.; Padilla, A.P.; Campderrós, M.E. Inulin like lyoprotectant of bovine plasma proteins concentrated by ultrafiltration. Food Research International 2010, 43 (3), 788-796.

[12] Kim, Y.; Faqih, M.N.; Wang, S.S. Factors affecting gel formation of inulin. Carbohydrate Polymers 2001, 46 (2), 135-145.

[13] Murphy, E.W.; Criner, P.E.; Grey, B.C. Comparisons of methods for calculating retention in cooked foods. Journal of Agricultural and Food Chemistry 1975, 23 (6), 1153-1157.

[14] Praznik, W.; Cieślik, E.; Filipiak-Florkiewicz, A. Soluble dietary fibers in Jerusalem artichoke powders: Composition and application in bread. Nahrung 2002, 46 (3), 151157.

[15] Khuenpet, K.; Fukuoka, M.; Jittanit, W.; Sirisansaneeyakul, S. Spray drying of inulin component extracted from Jerusalem artichoke tuber powder using conventional and ohmic-ultrasonic heating for extraction process. Journal of Food Engineering 2017, 194, 67-78.

[16] Afoakwah, N.A.; Dong, Y.; Zhao, Y.; Xiong, Z.; Owusu, J.; Wang, Y.; Zhang, J. Characterization of Jerusalem artichoke (Helianthus tuberosus L.) powder and its application in emulsion-type sausage. LWT - Food Science and Technology 2015, 64 (1), 74-81.

[17] Prabhu, G.; Husak, R. Use of sodium carbonate and native potato starch blends as phosphate replacer in natural enhanced pork loins. Meat Science 2014, 96 (1), 454-455. 